\title{
Infectious endocarditis caused by Helcococcus kunzii in a vascular patient: a case report and literature review
}

Romain Lotte ${ }^{1,4^{*}}$, Laurène Lotte ${ }^{1}$, Nicolas Degand ${ }^{1}$, Alice Gaudart ${ }^{1}$, Sylvie Gabriel ${ }^{2}$, Mouna Ben H'dech³, Mathilde Blois ${ }^{1}$, Jean-Paul Rinaldi ${ }^{3}$ and Raymond Ruimy ${ }^{1,4}$

\begin{abstract}
Background: Helcococcus kunzii is a facultative anaerobic bacterium that was first described by Collins et al. in 1993, and was initially considered as a commensal of the human skin, in particular of lower extremities. Human infections caused by $\mathrm{H}$. kunzii remain rare with only a few cases published in the pubmed database. Nevertheless recent reports indicate that this microorganism has to be considered as an opportunistic pathogen that can be involved in severe infections in human. To the best of our knowledge, we describe here the first known case of infectious endocarditis caused by H. kunzii.

Case presentation: A 79 year-old man reporting severe polyvascular medical history attended the emergency ward for rapid deterioration of his general state of health. After physical examination and paraclinical investigations, the diagnosis of infectious endocarditis on native mitral valve caused by Helcococcus kunzii was established based on Dukes criteria. MALDI-TOF mass spectrometry and $16 \mathrm{~S}$ rDNA sequencing allowed an accurate identification to the species level of Helcococcus kunzii. The patient was successfully treated by a medico-surgical approach. The treatment consisted in intravenous amoxicillin during four weeks and mitral valve replacement with a bioprosthestic valve. After an in depth review of patient's medical file, the origin of infection remained unknown. However, a cutaneous portal of entry cannot be excluded as the patient and his General Practitioner reported chronic ulcerations of both feet.

Conclusions: We describe here the first case of endocarditis caused by $H$. kunzii in an elderly patient with polyvascular disease. This report along with previous data found in the literature emphasizes the invasive potential of this bacterial species as an opportunistic pathogen, in particular for patient with polyvascular diseases. MALDI-TOF mass spectrometry and 165 rDNA sequencing are reliable tools for $\mathrm{H}$. kunzii identification. We also sequenced in this work H.kunzii type strain 103932T CIP and deposited in the Genbank under accession number KM403387. We noticed a 14 base difference between our sequence and the original sequence deposited by Collins et al. under Genbank accession number X69837. Hopefully, the spread of next generation sequencing tools would lead to a more accurate classification of clinical strains.
\end{abstract}

\section{Background}

Helcococcus kunzii is a facultative anaerobic bacterium that was first described by Collins et al. in 1993, and was initially considered as a commensal of the human skin [1-3]. Recent reports of invasive infections caused by $H$. kunzii indicate that this microorganism has to be considered as an opportunistic pathogen that can be involved in severe infections

\footnotetext{
*Correspondence: lotte.r@chu-nice.fr

${ }^{1}$ Department of Bacteriology at Nice Academic Hospital, Nice, France

${ }^{4}$ Nice Medical University, Nice-Sophia Antipolis University, Nice, France Full list of author information is available at the end of the article
}

in human [4-6]. We describe here the first known case of infectious endocarditis caused by $H$. kunzii in a patient with polyvascular disease and further provide a short review of the literature on infections related to $H$. kunzii.

\section{Case Presentation}

A 79 year-old man attended the emergency ward in February 2014 for chills, diarrheas, and a rapid deterioration of his general state of health. The patient was a former heavy smoker and also suffered from alcoholism, dyslipidemia and high blood pressure. He had no history

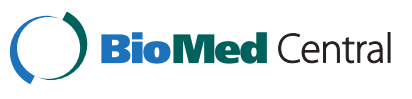


of drug use. Noteworthy medical history consisted in ischemic heart disease treated by coronary angioplasty in 2002, left and right carotid surgery by endarterectomy successively in 2004 and 2008, and a vascular stenting of an abdominal aortic aneurysm in 2010 .

On admission, hemodynamic status was stable. The pulse rate was 81 beats/min and respiratory rate was normal. Body temperature was $38.5{ }^{\circ} \mathrm{C}$. Interestingly, the auscultation showed light bilateral crackles in the lower third of lungs, a systolic mitral murmur grade III/IV and no carotid murmur. No sign of thrombophlebitis of the lower limbs was found. Laboratory investigations revealed inflammatory markers such as elevated C-reactive protein $(114 \mathrm{mg} / \mathrm{L})$, leukocytosis $\left(18 \times 10^{9} / \mathrm{L}\right)$ and normocytic anaemia $(12 \mathrm{~g} / \mathrm{dL})$. Considering the clinical and laboratory investigations, infectious endocarditis (IE) was suspected and the patient was promptly transferred to the department of cardiology.

Transesophageal echocardiography (TEE) visualized a $28.6 \mathrm{~mm}$ vegetation on the mitral valve (Fig. 1), and a 3D color Doppler showed a severe valve dysfunction with mitral regurgitation, which was consistent with mitral IE on native valve. A complete imaging workup, including spinal cord and brain magnetic resonance imaging, did not detect any other septic location. Of note, abdominal computed tomography did not show any perigraft fluid or other evidence of suspicion of an infected aortic vascular graft. The ocular examination of the patient was normal. Three sets of blood cultures were successively drawn (one set every $12 \mathrm{~h}$ ) on the day of admission and the day after. Blood cultures were processed with a Bactalert 3D system (BioMérieux, France). Four out of six blood culture bottles ( 3 anaerobic and 1 aerobic) grew respectively in $7,8,24$ and $72 \mathrm{~h}$. The remaining aerobic bottles were negative after prolonged incubation (up to 28 days). Gram staining directly performed on the positive blood cultures yielded Gram-positive cocci arranged in clumps. Cultures grew aerobically and anaerobically on Columbia agar plates supplemented with $5 \%$ sheep blood (BioMérieux, Marcy l'Etoile, France) after $24 \mathrm{~h}$ of incubation as non-hemolytic, grey, pinpoint colonies. Catalase and oxidase reactions were negative. Phenotypic characterization using API system (BioMérieux, API 20 Strep) did not provide any reliable identification (Aerococcus viridans with a doubtful significance, numerical profile: 4100413). In order to achieve an acute bacterial identification the strain was sent to our laboratory (Nice University Hospital). Matrix-assisted laser desorption/ ionization time of flight (MALDI-TOF) mass spectrometry using Microflex LT with Biotyper v2.3 database (Bruker Daltonics, Bremen, Germany) directly on colonies identified Helcococcus kunzii (log score value of 2.38 matching with $H$. kunzii type strain CIP 103932T). Identification was confirmed by $16 \mathrm{~S}$ rDNA gene sequencing on colonies using forward (A2: 5'AGAGTTTGATCATGGCTCAG3') and reverse (S15: 5'GGGCGGTGTGTACAAGGCC3') primers as previously described [7]. Blast analysis of the partial 16S rDNA sequence of our strain (1346 nucleotides, deposited in Genebank under accession number KM403388) showed 98.9 \% identity (14 nucleotides differences) with $16 \mathrm{~S}$ rDNA sequence of $H$. kunzii CIP $103932 \mathrm{~T}$ deposited in Genbank under accession number X69837 by Collins et al. in 1993 when they first described this species [1]. Antimicrobial susceptibility testing (AST) was performed using the E-test method on Mueller-Hinton agar supplemented with $5 \%$ sheep blood (BioMérieux, Marcy l'Etoile, France) incubated at

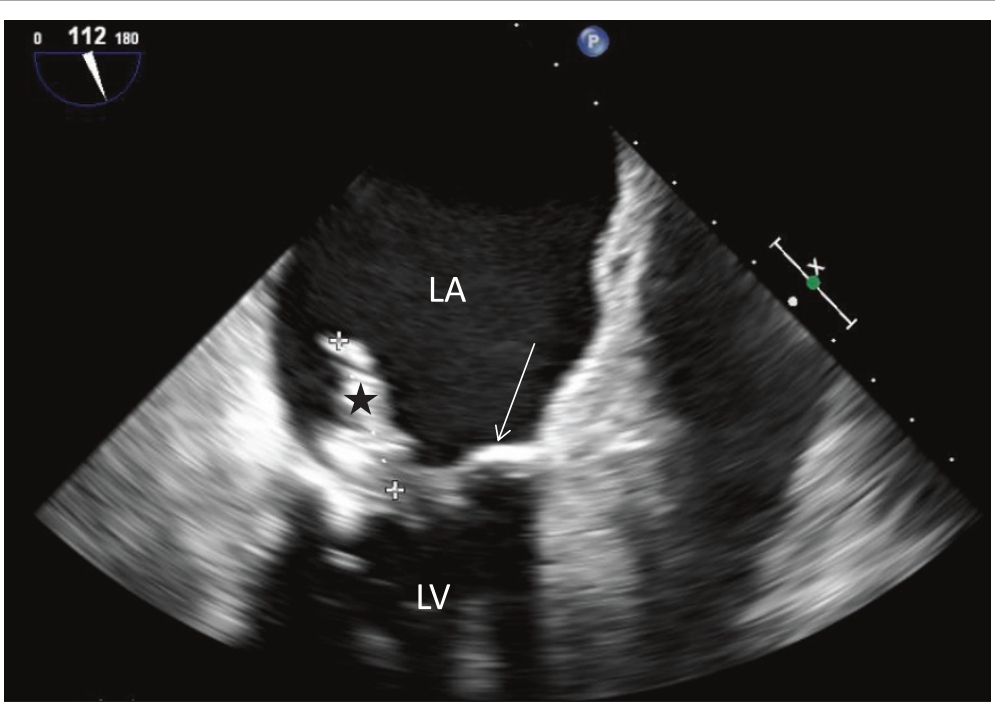

Fig. 1 Transesophageal echocardiogram of infected native mitral valve. Echocardiography visualized a 28.6 mm multilobulated vegetation (black star), attached to the native mitral valve (arrow). Left atrium (LA). Left ventricle (LV). The 3D color Doppler (not shown) revealed a severe valve dysfunction with mitral regurgitation 
$36{ }^{\circ} \mathrm{C}$ in $5 \% \mathrm{CO}_{2}$ for $24 \mathrm{~h}$ according to the Clinical and Laboratory Standards Institute (CLSI) interpretative standard for Streptococcus species [8]. The strain was highly susceptible to all $\beta$-lactams tested. It was also susceptible to clindamycin, and vancomycin, but had reduced susceptibility to gentamicin. The MICs $(\mu \mathrm{g} / \mathrm{L})$ of drugs for this strain are reported in Table 1 . The patient was initially treated empirically with intra-venous amoxicillin $(100 \mathrm{mg} /$ $\mathrm{kg}$ per day) and gentamicin adapted to the renal function. Once the results of the blood cultures were available, the treatment was followed by intra-venous amoxicillin monotherapy $(100 \mathrm{mg} / \mathrm{kg}$ per day) for a total duration of 4 weeks. 5 days after admission, the patient underwent a mitral valve replacement with a bioprosthestic valve. Vegetation length $(>15 \mathrm{~mm})$ is a strong predictor of new embolic-event and constituted therefore a major indication for mitral valve surgery in this patient according to the guidelines of the European society of cardiology [9]. Bacteriological analysis of the mitral valve was negative after 5 days of incubation but there was not enough valve tissue remaining for $16 \mathrm{~S}$ rDNA PCR analysis. A total of three blood culture sets at days 5 and 6 after admission remained negative despite prolonged incubation up to 4 weeks. Control echocardiography 3 weeks after surgery resulted normal. Moreover, biological and clinical follow-up at 3 and 6 months confirmed a fullsustained cardiac recovery. At 6 months, the complete physical examination only retrieved right hallux ulceration for which microbiological analysis only detected few colonies of Klebsiella pneumoniae and Staphylococcus epidermidis, but remained negative for anaerobic bacteria.

\section{Discussion}

The first description of the genus Helcococcus was made by Collins et al. in 1993, based on $16 S$ rDNA sequencing and phylogenetic analysis of a collection of 9 strains of Aerococcus-like organisms isolated from human clinical sources [1]. Within this genus, H. kunzii was the first species to be characterized (type strain NCFB 2900/CIP 103932T) [1] followed by the species: Helcococcus pyogenes, Helcococcus sueciensis, Helcococcus ovis [10] and recently Helcococcus seattlensis [11]. Briefly, $H$. kunzii is a catalase-negative, facultative anaerobic, non-motile Gram-positive coccus whose

Table 1 Antimicrobial susceptibilities of Helcococcus kunzii determined with the E-test method and clinical categorization

\begin{tabular}{lll}
\hline Antimicrobial agent & $\mathrm{MIC}(\mu \mathrm{g} / \mathrm{mL})$ & Clinical categorization \\
\hline Penicillin G & $<0.016$ & $\mathrm{~S}$ \\
Amoxicillin & $<0.016$ & $\mathrm{~S}$ \\
Amoxicillin + clavulanic acid & $<0,016$ & $\mathrm{~S}$ \\
Cefotaxime & $<0,016$ & $\mathrm{~S}$ \\
Clindamycin & 0.032 & $\mathrm{~S}$ \\
Gentamicin & 1,5 & $\mathrm{I}$ \\
Vancomycin & 0,38 & $\mathrm{~S}$ \\
\hline
\end{tabular}

cells are arranged in pairs and clusters. The organism grows slowly, producing pinpoint translucent to greyish, non-haemolytic or slightly alpha-haemolytic colonies after $24 \mathrm{~h}$ incubation on blood agar, with no difference of growth under $5 \% \mathrm{CO}_{2}$ or anaerobic conditions $[1,2]$. Biochemical methods are not reliable for $\mathrm{H}$. kunzii identification, as assessed by several reports mentioning misidentification of $H$. kunzii as Aerococcus sp. or Aerococcus viridans $[1,3-5,12,13]$. In this particular case, phenotypic characterization using API system (BioMérieux, API 20 Strep) misidentified the strain as Aerococcus viridans with a doubtful significance (numerical profile: 4100413 ) as previously described $[1,3-5,12,13]$. MALDI TOF Mass spectrometry allowed an accurate species level identification of our strain (log score value of 2.38 matching with H. kunzii type strain CIP $103932 \mathrm{~T}$ ). This point can be explained by the expanding MALDI-TOF databases which enable this technique to identify such unfrequently encountered organisms. $16 S r D N A$ sequencing confirmed the species level identification obtained by MALDI-TOF mass spectrometry. In this work we further performed $16 \mathrm{~S} r D N A$ sequencing on the type strain CIP 103932T using primers previously described [7] and we deposited it in the Gene Bank under accession number KM403387. Nucleotide sequence alignment with BioEdit (http://www.mbio.ncsu.edu/BioEdit/) between type strain sequence accession number KM403387 and $16 S$ rDNA sequence of our $H$. kunzii clinical strain showed there were $0(0 \%)$ base difference. Interestingly, when performing sequence alignment with BioEdit between our sequence of $H$. kunzii type strain (accession number KM403387) and the Gene Bank deposited H. kunzii type strain (sequence X69837) first described by Collins et al. [1] we found a $14(1,05 \%)$ base difference. The manual sequencing method used by Collins et al. when they first described H. kunzii [14] could explain this 14 base pair difference between the two sequences. Hopefully, the spread of new genomic tools such as whole-genome sequencing will help to minimize this type of error that are persisting in bacterial $16 \mathrm{~S}$ bank databases and will also lead to a an accurate classification of bacterial species based on the whole genome sequence.

Concerning the clinical features, several authors already reported data concerning $H$. kunzii. This bacterium was first considered to be part of the normal flora of the human skin, in particular of lower extremities [2, 3]. More recently, it has been shown to be involved in human infections either in mixed bacterial cultures such as diabetic foot infection [15], plantar phlegmon [16], chronic osteomyelitis of the tibia [17], or severe monobacterial infections such as prosthetic joint infection [4], implantable cardiac device infection [6], abscesses [11-13, 18] empyema, bacteraemia [5] and central nervous system infection [19]. The main clinical and microbiological features of these infections are shown in Table 2. To the best of our 
Table 2 Main features of reported cases of Helcococcus kunzii infections

\begin{tabular}{|c|c|c|c|c|c|c|c|}
\hline $\begin{array}{l}\text { Sex/age of } \\
\text { patient (years) }\end{array}$ & $\begin{array}{l}\text { Underlying } \\
\text { condition(s) }\end{array}$ & Type of infection & Treatment & Outcome & Other bacteria & Methods of identification & Author \\
\hline $\mathrm{M} / 41$ & IV-drugs user & Bacteraemia & $\begin{array}{l}3 \text { weeks of penicillin } \mathrm{G} \text { and } \\
\text { cloxacillin IV }\end{array}$ & Recovery & None & $\begin{array}{l}\text {-API } 20 \text { Strep system, (bioMérieux, } \\
\text { Marcy l'Etoile, France), (code 4100413) } \\
\text {-16S rDNA gene sequencing }\end{array}$ & Woo et al. 2005 [5] \\
\hline$M / 83$ & $\begin{array}{l}\text { Hypertension, } \\
\text { diabetes, prostate } \\
\text { cancer }\end{array}$ & Brain abscess & $\begin{array}{l}2 \text { weeks of ceftriaxone and } \\
\text { metronidazole IV, then oral } \\
\text { amoxicillin-clavulanic acid } \\
\text { and then ceftriaxone and } \\
\text { metronidazole and vancomycin } \\
\text { IV. Total duration of antimicrobial } \\
\text { therapy } 12 \text { weeks. }\end{array}$ & Recovery & None & $\begin{array}{l}\text {-Vitek2 system, (bioMérieux, Marcy } \\
\text { I'Etoile, France) } \\
\text {-Matrix-assisted laser } \\
\text { desorption time-of-flight mass } \\
\text { spectrometry (MALDI-TOF MS; Vitek } \\
\text { MS bioMérieux) } \\
\text {-16S rDNA gene sequencing }\end{array}$ & Sridhar et al. 2014 [19] \\
\hline$M / 55$ & $\begin{array}{l}\text { Smoker, alcoholic } \\
\text { and IV-drugs user }\end{array}$ & Empyema thoracic & $\begin{array}{l}8 \text { weeks of amoxicillin-clavulanic } \\
\text { acid }\end{array}$ & Recovery & None & $\begin{array}{l}\text {-API } 20 \text { Strep system, (code 4100413) } \\
\text {-16S rDNA gene sequencing }\end{array}$ & Woo et al.2005 [5] \\
\hline$M / 39$ & Osteochondritis & $\begin{array}{l}\text { Prosthetic joint } \\
\text { chronic infection }\end{array}$ & Clindamycin and gentamicin & Recovery & None & $\begin{array}{l}\text {-API } 20 \text { Strep system,(code } \\
4100413) \\
-16 S \text { rDNA gene sequencing }\end{array}$ & Perez-Jorge et al. 2011 [4] \\
\hline$M / 75$ & NA & $\begin{array}{l}\text { Infection of } \\
\text { implantable cardiac } \\
\text { device }\end{array}$ & $\begin{array}{l}\text { Association of flucloxacilline } \\
(2 \mathrm{~g} \times 4 / \text { day) and benzylpenicllin } \\
(2.4 \times 4 / \text { day) IV then association of } \\
\text { vancomycin and clindamycin } \\
\text { ( } 14 \text { days) IV and then association } \\
\text { of oral amoxicillin and rifampicin } \\
\text { for four weeks }\end{array}$ & Recovery & None & $\begin{array}{l}\text {-BBL Crystal }{ }^{T M} \text { System (Baltimore, MD, } \\
\text { USA)-BD Phoenix }{ }^{T M} \text { Automated } \\
\text { Microbiology System (Baltimore, MD, } \\
\text { USA) } \\
\text {-16S rDNA gene sequencing }\end{array}$ & Mc Nicholas et al. 2011 [6] \\
\hline W/57 & None & Breast abscess & $\begin{array}{l}\text { Oral cephalexin ( } 0.5 \mathrm{~g} / \text { day }) \\
\text { for } 5 \text { days }\end{array}$ & Recovery & None & $\begin{array}{l}\text {-API 20S Strep system, (code } \\
4100413 \text { ), } \\
\text {-16S rDNA gene sequencing }\end{array}$ & Chagla et al. 1998 [13] \\
\hline W/36 & None & $\begin{array}{l}\text { Post chirurgical } \\
\text { foot abscess }\end{array}$ & Pristinamycine and rifampicin & Recovery & None & $\begin{array}{l}\text {-Rapid ID } 32 \text { Strep system } \\
\text { (bioMérieux, Marcy l'Etoile, France), } \\
\text { (Aerococcus viridans) } \\
\text {-16S rDNA gene sequencing }\end{array}$ & Riegel et al. 2003 [18] \\
\hline$M / 36$ & $\begin{array}{l}\text { High blood pressure, } \\
\text { obesity and } \\
\text { hypercholesterolemia }\end{array}$ & $\begin{array}{l}\text { Sebaceous cyst } \\
\text { infection associated } \\
\text { with cellulitis }\end{array}$ & $\begin{array}{l}\text { Flucloxacillin }(1 \mathrm{~g} \times 4 / \text { day }) \text { IV and } \\
\text { then oral flucloxacillin }(0.5 \mathrm{~g} \times 4 / \\
\text { day) for } 5 \text { days }\end{array}$ & Recovery & None & $\begin{array}{l}\text {-API } 20 \text { Strep system, (code } \\
4100413 \text { ) }\end{array}$ & Peel et al. 1997 [12] \\
\hline$M / 86$ & $\begin{array}{l}\text { Malignant melanoma } \\
\text { and congenital } \\
\text { thrombocytopenia }\end{array}$ & Osteomyelitis & $\begin{array}{l}\text { Cefuroxime }(3 \times 1.5 \mathrm{~g} / \text { day }) \text { and } \\
\text { metronidazole }(2 \times 500 \mathrm{mg} / \text { day }) \\
\text { and then amoxicillin-clavulanic } \\
\text { acid }(2 \times 1 \mathrm{~g} / \text { day }) \text { for } 6 \text { weeks PO }\end{array}$ & Recovery & $\begin{array}{l}\text { Anaerobic bacteria and } \\
\text { germs of normal skin flora }\end{array}$ & Not available & Stanger et al. 2013 [17] \\
\hline$M / 68$ & $\begin{array}{l}\text { Coronary artery } \\
\text { disease and colonic } \\
\text { polyps }\end{array}$ & $\begin{array}{l}\text { Inner thigh wound } \\
\text { from trauma }\end{array}$ & $\begin{array}{l}\text { Vancomycin and piperacillin- } \\
\text { tazobactam inpatient and } \\
\text { cephalexin outpatient }\end{array}$ & NA & Staphylococcus aureus & $\begin{array}{l}\text {-API } 20 \text { Strep system and VITEK } 2 \\
\text { (bioMérieux, Marcy l'Etoile, France), } \\
\text {-16S rDNA gene sequencing }\end{array}$ & Chow et al. 2014 [11] \\
\hline$M / 25$ & $\begin{array}{l}\text { Post-traumatic stress } \\
\text { disorder }\end{array}$ & Toe abscess & Sulfamethoxazole, cephalexin & NA & Staphylococcus aureus & $\begin{array}{l}\text {-API } 20 \text { Strep system and VITEK 2, } \\
\text {-16S rDNA gene sequencing }\end{array}$ & Chow et al. 2014 [11] \\
\hline
\end{tabular}


Table 2 Main features of reported cases of Helcococcus kunzii infections (Continued)

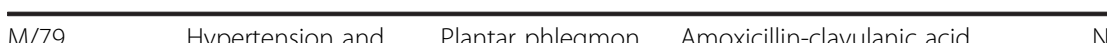

NA

Klebsiella oxytoca

Bacteroides fragilis

-VITEK 2 GP card identification

system (bioMérieux, Marcy l'Etoile,

Lemaître et al. 2008[16]

severe intermittent

(3 weeks), surgical debridement

Proteus mirabilis

France)

both legs

phlegmon

$\begin{array}{ll}\text { M/58 Diabetes and end- } & \text { Ulcerative lesion } \\ \text { stage renal disease of foot }\end{array}$

3 weeks of piperacillin/tazobactam IV Recovery Proteus mirabilis

-16S rDNA gene sequencing

-Matrix-assisted laser desorption

time-of-flight mass spectrometry

(MALDI-TOF MS; Bruker GmbH,

Bremen, Germany)

-Vitek2 GP system (bio-Mérieux

Marcy l'Etoile, France)

-165 rDNA gene sequencing 
knowledge, we report here the first known case of IE caused by $H$. kunzii in an elderly patient with polyvascular disease. According to the modified Duke Criteria for a definitive diagnosis of IE [20], the patient met one major criterion (new valvular regurgitation murmur and positive echocardiogram) and three minor criteria (fever, predisposing factor of heart condition and 3 blood cultures growing an organism that does not commonly cause endocarditis). Interestingly, the origin of infection remains unknown and was not assessed by any microbiological data. On admission, urine sample was positive with E.coli $10^{3} \mathrm{CFU} / \mathrm{mL}$. No other microbiological sample was sent to the laboratory for analysis. After an in depth review of the patient's medical file, it seems that he had no known intravenous drug use history. The patient was alcoholic and ex-smoker. He did not report any recent dental extraction before admission. The literature review suggests that $H$. kunzii is mostly involved in skin infection [11$13,15,16,18]$ and therefore cutaneous portal of entry cannot be excluded as the patient and his General Practitioner reported chronic ulcerations of both feet. Finally the AST performed on the strain confirmed the high susceptibility of $H$. kunzii to $\beta$-lactams previously demonstrated by several authors $[2,4-6,11-13$, $15,16,18,19]$. Further more, $H$. kunzii strains often displayed reduced susceptibility to aminoglycosides either gentamicin or amikacin $[4,11,18,19]$. This could have an impact on antimicrobial therapy as gentamicin is frequently prescribed in combination with betalactams for empirical coverage of IE. In our patient, a medico-surgical approach consisting in mitral valve replacement and combination of intravenous amoxicillin and gentamicin followed by amoxicillin monotherapy led to a full-sustained cardiac recovery. Altogether, considering the well-established synergistic activity of the $\beta$-lactam-aminoglycoside association, such combination might be used in case of IE caused by $H$. kunzii, even if the isolate displays reduced susceptibility to aminoglycosides. Nevertheless, further studies will be required to better characterize the antimicrobial susceptibility pattern of this newly recognized emerging pathogen.

\section{Conclusions}

We describe here the first case of endocarditis caused by $H$. kunzii in an elderly patient with polyvascular disease. Accurate identification of this uncommon species allowed by MALDI-TOF mass spectrometry emphasizes the growing importance of this technique in routine microbiological diagnosis. Interestingly, this report along with the previous cases of invasive infections caused by $H$. kunzii indicate that this recently discovered bacterium has to be considered as a true opportunistic emerging pathogen and not only as a commensal of the human skin as initially thought in its first description. $16 S$ rDNA sequencing confirmed the bacterial identification and allowed us to detect differences between two sequences of the same $H$. kunzii type strain (gene Bank accession numbers KM403387 and X69837) which could be explained by the sequencing methods performed and will have to be investigated by whole sequence analysis.

\section{Consent}

Written informed consent was obtained from the patient for publication of this case report and any accompanying images. A copy of the written consent is available for review by the Editor-in-Chief of this journal.

\section{Abbreviations \\ IE: Infectious endocarditis; TEE: Transesophageal echocardiography.}

\section{Competing interests}

The authors declare that they have no competing interests.

\section{Authors' contributions}

All authors drafted and helped to write the manuscript. All authors read and approved the final manuscript. RL: Wrote the manuscript (initial and revised version) and the response letter to reviewers' comments. Contributed to the acquisition of clinical and microbiological data. LL: Contributed to the acquisition of clinical and microbiological data. Helped to write the manuscript. Performed antimicrobial susceptibility testings on the clinical isolate. ND: Helped to write the initial and revised manuscript. Performed antimicrobial susceptibility testings on the clinical isolate. AG: Contributed to the acquisition of clinical and microbiological data. Helped to write the manuscript. SG: Contributed to the acquisition of microbiological data and drafted the manuscript. $\mathrm{MBH}$ : was the junior cardiologist in charge of patient clinical follow-up and contributed to the acquisition of clinical data. Drafted the initial and revised manuscript. MB: Contributed to the acquisition of clinical and microbiological data. Drafted the manuscript. JPR: was the senior cardiologist in charge of patient clinical follow-up and contributed to the acquisition of clinical data. Drafted the initial and revised manuscript. RR: Participated in the sequence alignment of the 165 sequences of the patient's strain. Drafted the manuscript.

\section{Acknowledgements}

We thank Dr Orane Visvikis (PhD) for careful reading of the manuscript and insightful comments.

\section{Author details}

${ }^{1}$ Department of Bacteriology at Nice Academic Hospital, Nice, France. 2Department of Medical Biology, Monaco Princess Grace General Hospital, Monaco, Monaco. ${ }^{3}$ Department of Cardiology, Monaco Princess Grace General Hospital, Monaco, Monaco. ${ }^{4}$ Nice Medical University, Nice-Sophia Antipolis University, Nice, France.

Received: 12 March 2015 Accepted: 12 June 2015

Published online: 23 June 2015

\section{References}

1. Collins M, Facklam R, Rodrigues U, Ruoff K. Phylogenetic analysis of some Aerococcus-like organisms from clinical sources: description of Helcococcus kunzii gen. nov., sp. nov. Int J Syst Bacteriol. 1993;43:425-9.

2. Caliendo A, Jordan C, Ruoff K. Helcococcus, a new genus of catalase-negative, gram-positive cocci isolated from clinical specimens. J Clin Microbiol. 1995:33:1638.

3. Haas J, Jernick S, Scardina R, Teruya J, Caliendo A, Ruoff K. Colonization of skin by Helcococcus kunzii. J Clin Microbiol. 1997;35:2759-61.

4. Perez-Jorge C, Cordero J, Marin M, Esteban J. Prosthetic joint infection caused by Helcococcus kunzii. J Clin Microbiol. 2012;50(2):528-30. 
5. Woo PC, Tse H, Wong SS, Tse CW, Fung AM, Tam DM, et al. Life-threatening invasive Helcococcus kunzii infections in intravenous-drug users and ermA-mediated erythromycin resistance. J Clin Microbiol. 2005;43(12):6205-8.

6. McNicholas S, McAdam B, Flynn M, Humphreys H. The challenges of implantable cardiac device infection due to Helcococcus kunzii. J Hosp Infect. 2011;78(4):337-8.

7. Ruimy R, Breittmayer V, Elbaze P, Lafay B, Boussemart O, Gauthier M, et al. Phylogenetic analysis and assessment of the genera Vibrio, Photobacterium, Aeromonas, and Plesiomonas deduced from small-subunit rRNA sequences. Int J Syst Bacteriol. 1994;44(3):416-26.

8. Clinical and Laboratory Standards Institute. Methods for antimicrobial susceptibility testing of Streptococcus viridans sp; approved standard, vol. 27, no2). 8th ed. Wayne, PA: M11-A8. CLSI; 2012.

9. Habib G, Hoen B, Tornos P, Thuny F, Prendergast B, Vilacosta I, et al. Guidelines on the prevention, diagnosis, and treatment of infective endocarditis (new version 2009): the task force on the prevention, diagnosis, and treatment of infective endocarditis of the European Society of Cardiology (ESC). Endorsed by the European Society of Clinical Microbiology and Infectious Diseases (ESCMID) and the International Society of Chemotherapy (ISC) for infection and cancer. Eur Heart J. 2009;30(19):2369-413.

10. Collins MD, Falsen E, Foster G, Monasterio LR, Dominguez L, FernandezGarazabal JF. Helcococcus ovis sp. nov., a gram-positive organism from sheep. Int J Syst Bacteriol. 1999;49 Pt 4:1429-32.

11. Chow SK, Clarridge 3rd JE. Identification and clinical significance of Helcococcus species, with description of Helcococcus seattlensis sp. nov. from a patient with urosepsis. J Clin Microbiol. 2014;52:3854-8.

12. Peel M, Davis J, Griffin K, Freedmann D. Helcococcus kunzii as sole isolate from an infected sebaceous cyst. J Clin Microbiol. 1997;35:328-9.

13. Chagla A, Borczyk A, Facklam R, Lovgren M. Breast abscess associated with Helcococcus kunzii. J Clin Microbiol. 1998;36:2377-9.

14. Huston RA, Thompson DE, Collins MD. Genetic interrelationships of saccharolytic Clostridium botulinum types B, E and F and related clostridia as revealed by small-subunit rRNA gene sequences. FEMS Microbiol Lett. 1993;108:103-10.

15. Park JM, Woo BM, Hong SK, Kim EC. First Korean case of Helcococcus kunzii bacteremia in a patient with diabetes. Ann Lab Med. 2014;34:484-6.

16. Lemaître N, Huvent D, Loïez C, Wallet F, Courcol R. Isolation of Helococcus kunzii from plantar phlegmon in a vascular patient. J Med Microbiol. 2008;:57:907-8.

17. Stanger KM, Albert F, Kneser U, Bogdan C, Horch R. Management of chronic osteomyelitis of the tibia with life-threatening complications under negative pressure wound therapy and isolation of Helcococcus kunzii. Int Wound J. 2013. doi:10.1111/iwj.12133.

18. Riegel P, Lepargneur JP. Isolation of Helcococcus kunzii from a post-surgical foot abscess. Int J Med Microbiol. 2003;293(6):437-9.

19. Sridhar S, Chan JF, Yuen KY. First report of brain abscess caused by satelliting phenotypic variant of Helcococcus kunzii. J Clin Microbiol. 2014;52(1):370-3.

20. Durack DT, Lukes AS, Bright DK. New criteria for diagnosis of infective endocarditis: utilization of specific echocardiographic findings. Duke Endocarditis Service. Am J Med. 1994;96(3):200-9.

\section{Submit your next manuscript to BioMed Central and take full advantage of:}

- Convenient online submission

- Thorough peer review

- No space constraints or color figure charges

- Immediate publication on acceptance

- Inclusion in PubMed, CAS, Scopus and Google Scholar

- Research which is freely available for redistribution 